\title{
ICU delirium - a diagnostic and therapeutic challenge in the intensive care unit
}

\author{
Katarzyna Kotfis ${ }^{1}$, Annachiara Marra ${ }^{2,3}$, E. Wesley Ely ${ }^{2,4}$ \\ ${ }^{1}$ Department of Anesthesiology, Intensive Therapy and Acute Intoxications, Pomeranian Medical University \\ in Szczecin, Poland \\ ${ }^{2}$ Division of Allergy, Pulmonary and Critical Care Medicine, Vanderbilt University Medical Center, Nashville, \\ Tennessee, USA \\ ${ }^{3}$ Department of Neurosciences, Reproductive and Odontostomatological Sciences, University of Naples, \\ Federico II, Naples, Italy \\ ${ }^{4}$ Geriatric Research, Education and Clinical Center (GRECC) Service, Department of Veterans Affairs Medical \\ Center, Tennessee Valley Healthcare System, Nashville, Tennessee, USA
}

\begin{abstract}
ICU delirium is a common medical problem occurring in patients admitted to the intensive care units (ICUs). Studies have shown that ICU delirium is associated with increased mortality, prolonged hospitalization, prolonged mechanical ventilation, costs and the occurrence of cognitive disoders after discharge from ICU.

The tools available for ICU delirium screening and diagnosis are validated tests available for all members if the medical team (physicians, nurses, physiotherapists). Their use for routine patient assessment is recommended by international medical and scientific societies. They have been implemented as Pain, Agitation, Delirium (PAD) Guidelines by the Society of Critical Care Medicine. Apart from monitoring, a strategy of prevention and treatment is recommended, based on non-pharmacological approach (restoration of senses, early mobilization, physiotherapy, improvement in sleep hygiene and family involvement) as well as pharmacological treatment (typical and atypical antipsychotics and dexmedetomidine). In this article, we present the risk factors of ICU delirium, available tools for monitoring, as well as options for prevention and treatment of delirium that can be used to improve care over critically ill patients.

Anaesthesiology Intensive Therapy 2018, vol. 50, no 2, 128-140

Key words: delirium, CAM-ICU, monitoring, critical care, ICU
\end{abstract}

ICU delirium is common among patients treated in intensive care units (ICUs) and yet its adverse effects on prognosis have only recently been recognised. The occurrence of ICU delirium increases mortality, length of hospital stay and mechanical ventilation, treatment costs and incidences of cognitive disturbances [1-3]. The questionnaire study conducted by Kotfis et al. [4] regarding the diagnosis and treatment of ICU delirium as well as attitudes to sedation in Poland has revealed the extent of the problem in our country. The findings were alarming showing inadequate knowledge about the problem among ICU staff members. ICU delirium is monitored only in $12 \%$ of ICUs; sedation > $24 \mathrm{~h}$ is predominantly induced with benzodiazepines which are also often used to treat delirium [4]. The study by Morandi et al. [5] evaluating the same aspect of management worldwide has demonstrated that monitoring of delirium was implemented in $70 \%$ of ICUs while a proven diagnostic tool was used only in $42 \%$ of them.

Some of the implicated causes of the situation observed in Poland are inadequate training and delayed implementation of tools for identification of delirium and for its algorithm-based treatment. The recommendations of the authors' group that aimed to improve the diagnosis and treatment of ICU delirium in our country included: 1) improvement of education among ICU staff members, starting with physicians, 2) introduction of guidelines for monitoring 
and treatment of delirium and sedation (the role of the Polish Society of Anaesthesiology and Intensive Therapy), and 3) everyday use of tools assessing delirium and sedation translated into Polish [4]. We reckon that disorders of consciousness occurring in ICU patients constitute a serious problem due to their sudden development and attributable poor prognosis; therefore, they should be diagnosed early and treated dynamically.

The tools for diagnosing delirium in critically ill patients are the tests verified in practice that can be used by any member of health care personnel (physicians, nurses, physiotherapists). Their use in routine examinations of ICU patients is recommended by international scientific societies. They were implemented into guidelines as Management of Pain, Agitation, and Delirium (PAD) published by the Society of Critical Care Medicine, German DAS guidelines or recommendations of expert teams (eCASH) [6-8]. Besides monitoring, it is recommended to apply the strategies for prevention and treatment of ICU delirium either based on non-pharmacological management (early ambulation and rehabilitation of patients, improved sleep hygiene) or pharmacological management (classical and atypical antipsychotic drugs, dexmedetomidine). The present article discusses the risk factors for ICU delirium, the monitoring tools available in Poland as well as preventive and therapeutic strategies that can improve the quality of care of critically ill patients.

\section{DEFINITION OF DELIRIUM}

According to psychiatric nomenclature, disorders of consciousness are divided into quantitative and qualitative. The former include: clouding of consciousness, somnolence, sopor and coma while the latter encompass delirium, oneiroid syndrome, obnubilation and confusion. However, in the ICD-10 and DSM-5 classifications the disorders of consciousness of various severities and psychopathological characteristics are specified under one entry as delirium not induced by alcohol and other psychoactive substances [9].

Delirium is defined as a disturbance of consciousness characterized by a sudden onset (hours or days) and a fluctuating course of attention accompanied by a change in perception or cognition. Delirium impairs the patient's ability to receive, process, store and recall information [9]. Importantly, attention deficits and cognitive changes cannot be accounted for by coexisting neurocognitive disturbances (e.g. dementia) or a significantly decreased level of consciousness (e.g. sedation or coma). Delirium should be differentiated from dementia, especially in elderly patients; dementia is the condition of generalized cognitive deficits, impaired memory and intellectual abilities developing over a considerably longer period of time than delirium (months, years). ICU delirium can overlap the underlying disease (dementia, post-stroke condition); therefore, it is essential to determine the patient's baseline functional status.

Not all the features of ICU delirium are visible in each patient; moreover, the severity of individual symptoms varies. According to the type of symptoms, delirium can be categorized into three subtypes: hyperactive, hypoactive and mixed [10]. Hyperactive delirium is characterised by agitation, anxiety and attempts to remove the external devices (face masks, intravenous lines, drains, catheters). Hypoactive delirium is characterised by withdrawal, somnolence and reduced responsiveness to stimuli. The mixed subtype occurs when the affected patient fluctuates between hyperactive and hypoactive states.

Delirium is an acute, usually reversible state that results directly from a disease, intoxication or withdrawal of psychoactive substances, use of drugs, effects of toxins and stress or combined action of all the factors mentioned above. The diagnosis of delirium identifies the disturbances of central nervous system (CNS) function, yet does not recognise their aetiology; therefore, the cause of dysfunction should be sought immediately.

\section{EPIDEMIOLOGY}

It should be stressed that ICU delirium is a vital issue as its incidence ranges from $32 \%$ to $87 \%$ and highly depends on the population studied and the diagnostic method used. According to epidemiological studies, the incidence of postoperative delirium is approximately $45-50 \%$; the highest incidence rate is found in ICU patients undergoing mechanical ventilation and reaches over $80 \%[11,12]$.

The two most common subtypes of delirium are mixed (54\%) and hypoactive delirium (44\%); the pure hyperactive form is extremely rare (1.6\%). Hypoactive delirium requires regular monitoring using validated tools as its diagnosis is not simple and involves withdrawn, excessively calm, and lethargic patients. Hypoactive delirium is more common in elderly patients and is associated with worse prognosis, with the 6 -month mortality being $32 \%$ as compared to $8.7 \%$ in the other subtypes of delirium [13].

\section{PROGNOSIS}

ICU delirium is a predictor of increased mortality, prolonged hospitalisation and mechanical ventilation, increased treatment costs as well as increased risks of reintubation and of transferring the affected patient to a longterm health care facility $[1,6,8,14]$. Its development is associated with a 3.2-fold increase in 6-month mortality and a twofold prolongation of hospitalisation [1]. Additionally, delirium is connected with long-term cognitive impairment, which has been observed in $70 \%$ of mechanically ventilated patients after one year of observation [12]. Table 1 presents the results of a meta-analysis assessing the effects of 
Table 1. Influence of delirium on hospital mortality in critically ill patients treated in ICUs [12]

\begin{tabular}{|c|c|c|c|c|}
\hline Study (author/year) & $\begin{array}{c}\text { Patients with delirium } \\
\text { (number of incidents/total) }\end{array}$ & $\begin{array}{l}\text { Patients without delirium } \\
\text { (number of incidents/total) }\end{array}$ & $\begin{array}{l}\text { Weight } \\
(\%)\end{array}$ & $\begin{array}{c}\text { Mantel-Haenszel random risk } \\
\text { ratio }(95 \% \mathrm{Cl})\end{array}$ \\
\hline Kishi (1995) & $9 / 38$ & $49 / 200$ & 4 & $0.97(0.52-1.80)$ \\
\hline Dubois (2001) & $6 / 38$ & $24 / 160$ & 3 & $1.05(0.46-2.39)$ \\
\hline Ely (2004); Millbrandt (2004) & $27 / 183$ & $1 / 41$ & 1 & $6.05(0.85-43.25)$ \\
\hline $\operatorname{Lin}(2004)$ & $14 / 22$ & $26 / 80$ & 5 & $1.96(1.25-3.06)$ \\
\hline Micek (2005) & $14 / 44$ & $8 / 49$ & 4 & $1.95(0.90-4.20)$ \\
\hline Roberts (2005) & $19 / 84$ & $20 / 101$ & 4 & $1.14(0.65-1.99)$ \\
\hline Thomason (2005) & $24 / 125$ & $8 / 136$ & 4 & $3.26(1.52-7.00)$ \\
\hline Ranhoff (2006) & $26 / 117$ & $14 / 284$ & 4 & $4.51(2.44-8.32)$ \\
\hline Plaschke (2007) & $7 / 17$ & $3 / 20$ & 2 & $2.75(0.84-9.00)$ \\
\hline Marquis (2007); Ouimet (2007a) & $96 / 189$ & $98 / 348$ & 6 & $1.80(1.45-2.24)$ \\
\hline Ouimet (2007b) & $76 / 243$ & $128 / 521$ & 6 & $1.27(1.00-1.62)$ \\
\hline $\operatorname{Lin}(2008)$ & $21 / 31$ & $38 / 120$ & 6 & $2.14(1.50-3.06)$ \\
\hline Page (2009) & $8 / 22$ & $5 / 49$ & 3 & $3.56(1.31-9.67)$ \\
\hline Spronk (2009) & $6 / 23$ & $5 / 23$ & 3 & $1.20(0.43-3.38)$ \\
\hline Lat (2009) & $15 / 84$ & $6 / 50$ & 3 & $1.49(0.62-3.59)$ \\
\hline Van Rompaey (2009) & $3 / 155$ & $4 / 368$ & 2 & $1.78(0.40-7.86)$ \\
\hline Tsuruta (2010) & $2 / 21$ & $0 / 82$ & 1 & $18.86(0.94-378.80)$ \\
\hline Salluh (2010) & $18 / 75$ & $13 / 157$ & 4 & $2.90(1.50-5.60)$ \\
\hline Shehabi (2010) & $69 / 228$ & $15 / 126$ & 5 & $2.54(1.52-4.25)$ \\
\hline Van den Boogaard (2010) & $54 / 332$ & $80 / 1408$ & 6 & $2.86(2.07-3.96)$ \\
\hline Van dem Boogaard (2011) & $73 / 411$ & $40 / 1202$ & 5 & $5.34(3.36-7.72)$ \\
\hline Tomasi (2011) & $10 / 43$ & $13 / 119$ & 4 & $2.13(1.01-4.49)$ \\
\hline Serafim (2012) & $7 / 43$ & $17 / 422$ & 3 & $4.04(1.78-9.20)$ \\
\hline Sharma (2012) & $36 / 75$ & $0 / 65$ & 1 & $63.39(3.97-1012.88)$ \\
\hline Klein (2014) & $94 / 558$ & $40 / 554$ & 6 & $2.33(1.64-3.31)$ \\
\hline Mehta (2014) & $58 / 226$ & $43 / 19$ & 6 & $1.16(0.82-1.63)$ \\
\hline Almeida (2014) & $110 / 161$ & $3 / 9$ & 3 & $2.05(0.81-5.19)$ \\
\hline Tsuruta (2014) & $8 / 115$ & $0 / 65$ & 1 & $9.67(0.57-164.91)$ \\
\hline Total $(95 \% \mathrm{Cl})$ & $910 / 3703$ & $701 / 6953$ & 100 & 2.19 (1.78 to 2.70$)$ \\
\hline
\end{tabular}

delirium on hospital mortality of ICU patients carried out by Salluh et al. [12].

\section{RISK FACTORS}

The literature reports describe more than 25 factors significantly increasing the risk of delirium, including respiratory diseases, advanced age, alcohol abuse, dementia, ionic imbalance, demand for vasopressors, increased doses of opioids, or metabolic acidosis. The identified risk factors can be divided into the factors predisposing to and accelerating the development of delirium [15] (Table 2). Advanced age, senile frailty and a severe systemic disease (especially of the respiratory system) substantially increase the risk of delirium [16]. Likewise, advanced age correlated with cognitive impairment and memory deficits is a risk factor of delirium in acute conditions.
It appears that patients with reduced functional reserve, physical or mental, have poorer abilities to maintain proper CNS function in response to stress, such as a severe systemic disease (e.g. sepsis) or surgery, which increases the risk of delirium [17]. Moreover, inadequate pain management, especially post-operative, can induce delirium by impairing neurotransmission; in such cases pain becomes a factor inducing stressogenic disturbances of neuronal transmission [18].

Among the drugs that can be associated with the development of delirium, anticholinergic agents, benzodiazepines, steroids and long-acting opioids are essential, particularly in older individuals. In the group of benzodiazepines (clonazepam, diazepam, lorazepam, estazolam), all the drugs are potential inducers of ICU delirium; therefore, their use should be limited, especially in elderly patients [19]. 
Table 2. Risk factors for ICU delirium [15]

\begin{tabular}{lll}
\hline Predisposing factors & Precipitating factors & $\begin{array}{c}\text { Drugs precipitating the } \\
\text { development of delirium }\end{array}$ \\
\hline & Disorders precipitating the development of delirium & 1. Benzodiazepines \\
\hline 1. Older age & 1. Metabolic disorders & 2. Opioids (morphine) \\
2. History of cognitive disorders & 2. lon disorders & 3. Anticholinergic drugs \\
3. Frailty & 3. Hypotension & 4. Steroids \\
4. Alcohol and drug abuse & 4. Sepsis & 5. Deep sedation \\
5. Severity of the underlying & 5. Inadequate pain management & \\
disease & 6. Mechanical ventilation & \\
& 7. Sleep disorders & 8. Complicated surgery (abdominal cavity, cardiac surgery, femoral neck
\end{tabular}

The opioids most strongly associated with the occurrence of delirium are morphine and meperidine due to their long action and the risk of accumulation, particularly in patients with liver and/or kidney failure [16]. Relatively short-acting opioids should be chosen, such as fentanyl or remifentanil, which do not undergo metabolism to active metabolites and whose action does not lengthen in cases of liver or kidney disorders [20]. Moreover, the depth of sedation is important for the development of delirium - deep sedation is a causative factor, as compared to light sedation and daily sedation interruption [19, 21]. Furthermore, the duration of drug action and the risk of accumulation in tissues is of relevance; therefore, propofol or dexmedetomidine are preferred for sedation. Anticholinergic drugs (e.g. prometazine, difenhydramine, amitriptyline, doxepine, chlorpromazine) impair proper neurotransmission, which can lead to the development of delirium [22]. According to some studies, the use of steroids is associated with delirium, most likely as a consequence of adverse side effects of this group of drugs [23].

\section{PATHOPHYSIOLOGY}

The detailed presentation of pathophysiology of acute mental disorders in ICU patients is beyond the scope of this review; however, it should be stressed that the pathogenesis of delirium is multifactorial. One of the hypothesis assumes that the cascade of events starts with a generalised inflammatory reaction, endothelial dysfunction, increased permeability of the blood-brain barrier and reduced cholinergic control over the inflammatory response, which combined with the body debility predispose to the development of inflammatory changes in the nervous tissue, damage to neurons and overreactive responses of microglial cells [15, 24].

Delirium may be caused by decreased cholinergic activity [25]. Additionally, it should be emphasised that the use of anticholinergic drugs is found to be associated with the development of delirium manifestations. Another mechanism assumes overactivity of the dopaminergic system. Both increased activity of serotonin and its relative deficiency are associated with higher incidences of this pathology. Moreover, genetic predisposition is of importance [24].

\section{CAUSES OF DELIRIUM}

Noteworthy, the occurrence of delirium should be considered an alarming signal of impaired CNS functioning. The search for a possibly reversible cause should precede the treatment as in many cases the correction of one element in a short time improves the patient's condition. The ICU Delirium Study Group at the Vanderbilt University suggested an easy-to-remember mnemonic for quick analysis of delirium causes, presented in Figure 1.

\section{DIAGNOSIS OF DELIRIUM IN THE INTENSIVE CARE UNIT}

The majority of cases of ICU delirium remains undiagnosed. The gold standard for diagnosis of this pathology is the use of the fifth edition of the Diagnostic and Statistical Manual of Mental Disorders (DSM-5) criteria by a consulting psychiatrist, which is not feasible due to practical reasons [9]. Noteworthy, even well-trained medical personnel diagnoses less than a third of delirium cases, when none of the diagnostic tools are used; therefore, the current guidelines and recommendations advise the use of validated scales for early diagnosis of ICU delirium [6-8].

The assessment of delirium is possible only in patients responding to voice; therefore, it is necessary to apply the scale of sedation/disorders of consciousness; the recommended scales are the Richmond Agitation-Sedation Scale(RASS) or the Sedation-Agitation Scale (SAS) [26]. The scales most widely used in delirium monitoring and recommended by CCM [6] include the Confusion Assessment Method for the Intensive Care Unit (CAM-ICU) [27] and the Intensive Care Delirium Screening Checklist (ICDSC) [28].

Several tools for delirium diagnosis are used in clinical practice; however, until 2015 none of them has been translated into Polish. The most studied tool officially available on the ICU Delirium Study Group website since November 2015, also in Polish, is the CAM-ICU. The method was designed to assess delirium in mechanically ventilated ICU patients and 
STOP — remove all prodeliric drugs/consider withdrawal syndromes

benzodiazepines

anticholinergic drugs (metoclopramide, $\mathrm{H}$ 2-blockers, promethazine, diphenhydramine)

steroids

T. H. I. N. K.

Toxins: congestive heart failure, shock, dehydration, delirium-inducing drugs, new failure (of the liver, kidneys)

Hypoxemia

Infections/sepsis, Inflammation, Immobilisation, or a new hospital Infection?

Non-pharmacological interventions: early mobility/early exercises, hearing aid, glasses, time and space orientation, sleep hygiene, music, noise

control

$\mathbf{K}^{+}$disturbances and disturbances of other electrolytes, metabolic disturbances

LASTLY MEDICATE:

Classical antipsychotic drugs (e.g. haloperidol)

Atypical antipsychotic drugs (e.g. quetiapine)

Alfa-2 agonists (e.g. dexmedetomidine, clonidine)

Figure 1. Prevention of and early interventions for ICU delirium

presently awaits validation of its Polish version. The materials in Polish for practical application of CAM-ICU are available on http://www.icudelirium.org/delirium/languages.html and http://www.proicu.pl.

The Confusion Assessment Method (CAM) was designed in 1990 by doctor Sharon Inouye as a tool for bedside assessment of delirium by the staff without psychiatric education [29]. The CAM-ICU scale designed by the group of Ely et al. in 2011 is an adaptation of this tool for the needs of ICU patients, which enables its use in mechanically ventilated patients, both verbally communicating and non-verbal [27]. The CAM-ICU defines delirium by assessing four features considered diagnostic - sudden changes/fluctuations in mental status, inattention, disorganized thinking and altered levels of consciousness [27]. The first CAM-ICU validation study was conducted in 111 patients by two independent observers; the findings were compared with the assessment provided by a psychiatrist according to the DSM-IV criteria. The results have shown the specificity of $93 \%$ and $100 \%$ and the sensitivity of $98 \%$ and $100 \%$ [27]. Further studies have revealed the usefulness of the scale in routine assessment of ICU patients [26]. The meta-analysis carried out by Gusmao-Flores et al. [30] has demonstrated its pooled sensitivity of $80 \%$ and specificity of $96 \%$.

Another diagnostic tool, i.e. the Intensive Care Delirium Screening Checklist (ICDSC), assesses eight diagnostic criteria (altered level of consciousness, inattention, disorientation, psychosis, changes in psychomotor activity, inappropriate speech/mood, sleep disturbances and fluctuations of symptoms) [28]. Delirium can be diagnosed when four out of eight criteria are positive. According to the meta-analysis by Gusmao-Flores et al. [30], mentioned earlier, the pooled sensitivity of ICDSC is $74 \%$ while its specificity is $82 \%$.

It should be remembered that the evaluation of delirium is part of the work of an interdisciplinary team and requires cooperation of physicians, nurses, physiotherapists, and frequently the patient's family [31]. Delirium is of a changeable nature with fluctuations over 24 hours; therefore, the evaluation should be carried out several times a day to fully assess symptoms of the condition. For experienced raters, the time to perform CAM-ICU does not exceed 2 minutes. The screening tools should not be used only in university centres for research purposes; the implementation of CAM-ICU, however, requires trainings, didactic sessions and bedside teaching.

\section{STAGES OF ASSESSMENT}

The assessment of delirium is indeed an element of general assessment of the state of consciousness and is conducted in two stages. Consciousness is divided into two parts - the level of arousal and the content of consciousness. The first step is to assess its level, preferably using the Richmond Agitation-Sedation Scale (RASS), yet the CAM-ICU allows to apply also some other tools (Fig. 2). The next step is to assess the content of consciousness. In cases of more deeply altered levels of consciousness (i.e. RASS-4 and -5), it is difficult to assess the content as the patient does not respond to stimuli. These levels are called coma or stupor; in such cases the CAM-ICU is not applied as it is assumed that the patient does not qualify for evaluation. At higher levels of consciousness (i.e. RASS -3 and +4 ), it is possible to obtain at least the beginnings of meaningful reactions (i.e. response to voice). At the above levels, the clarity of thought can be assessed, thus the presence of delirium. The next step is to evaluate the content of consciousness (Fig. 3).

Step 1 - Assessment of the level of consciousness - RASS (Fig. 2).

Step 2 - Assessment of the content of consciousness - CAM-ICU (Fig. 3).

The content of consciousness is assessed using the CAMICU scale, which is discussed in detail in Figure 4 and below:

Feature 1 - Acute onset of mental status changes or a fluctuating course 


\begin{tabular}{|c|c|c|c|}
\hline Score & Condition & Description & Reaction \\
\hline+4 & aggressive & fights with the staff, endangers the staff & \\
\hline+3 & extremely agitated & tries to remove IV lines or catheters, aggressive & \\
\hline+2 & agitated & frequent non-purposeful movements, lack of cooperation with a ventilator & \\
\hline+1 & restless & worried or anxious, without aggressive movements & \\
\hline 0 & alert and calm & reacts spontaneously and listens to a caregiver & to voice \\
\hline-1 & drowsy & $\begin{array}{l}\text { not fully alert but fully consciously reacts to voice (eye opening and eye contact > } \\
10 \mathrm{sec} \text { ) }\end{array}$ & to voice \\
\hline-2 & light sedation & short-term awakening in response to voice (eye opening and eye contact < $10 \mathrm{sec}$ ) & to voice \\
\hline-3 & moderate sedation & eye movements or opening in response to voice (no eye contact) & to voice \\
\hline \multicolumn{4}{|c|}{ If RASS > or -3 , start CAM-ICU (positive or negative score) } \\
\hline-4 & deep sedation & no response to voice, movement to physical stimulation & to touch \\
\hline-5 & unrousable & no response to voice or physical stimulation & to touch \\
\hline \multicolumn{4}{|c|}{$\begin{array}{c}\text { If RASS }-4 \text { or }-5-\text { stop } \\
\text { monitoring (unconscious patient), } \\
\text { reassess later }\end{array}$} \\
\hline
\end{tabular}

Figure 2. Assessment of the level of consciousness - RASS (The Richmond Agitation Sedation Scale)

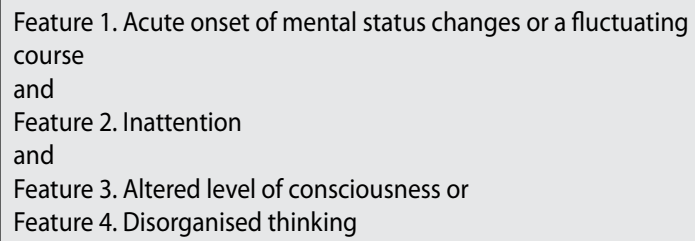

Figure 3. Assessment of the context of consciousness

Patients with delirium manifest sudden changes of mental status as compared to the baseline mental status and/ or mental status fluctuations. The baseline mental status is understood as the mental status prior to hospitalisation; in many cases, the patient's family or friends are asked to assess it or the data are obtained from the patient's medical history.

\section{Feature 2 - Inattention}

Alertness is the basic process of arousal which allows a conscious patient to react to various environmental stimuli. The individual who is alert but distracted reacts to each sound or movement. The individual who is attentive is able to ignore irrelevant stimuli.

\section{Feature 3 - Altered level of consciousness}

Patients with delirium experience altered levels of consciousness, which are assessed by the RASS scale. When the features 1 and 2 are absent, it is not necessary to examine the feature 3 . The feature 3 is present when the current consciousness level is anything other than RASS $=0$ (alert and calm).

\section{Feature 4-Disorganised thinking}

This is the most difficult stage in individuals who cannot speak as it is more extensively based on subjective assessment of a rater, as compared to other features. Intubation, mechanical ventilation and loss of motor functions limit the ability to cooperate of the majority of ICU patients. Therefore, to assess the level of organised thinking, the CAM-ICU uses simple questions and 2-degree commands. When the features 1 and 2 are absent, it is not necessary to examine this feature. The feature 4 is present when more than one error has been detected in both the answers to questions and responses to commands.

\section{PRACTICAL SUGGESTIONS}

Many cases of delirium are unrecognised; therefore, routine examinations for delirium should be carried out as part of physical examinations of all adult ICU patients. The examinations should be performed at least once during each nursing shift, i.e. every 8-12 hours and always whenever some changes in the patient's clinical status are observed. Additionally, attention should be paid to possible subclinical delirium when patients manifest only some symptoms of delirium. Prognosis in subclinical delirium is similar to that in fully symptomatic delirium, i.e. prolonged ICU stay and prolonged hospitalisation, as compared to non-delirious patients.

The occurrence of delirium is not confined to ICUs; therefore, several specialist versions of CAM-ICU have been developed for use outside ICUs, such as paediatric CAM-ICU (pCAM-ICU) approved for patients aged 5-17 years; Delirium Triage Screen (DTS) - a shortened version for institutions (departments) with extremely high bed occupancy rates; Brief CAM (bCAM) - designed for emergency departments. More information can be found on: http://www.icudelirium. org/non-icu.html. 


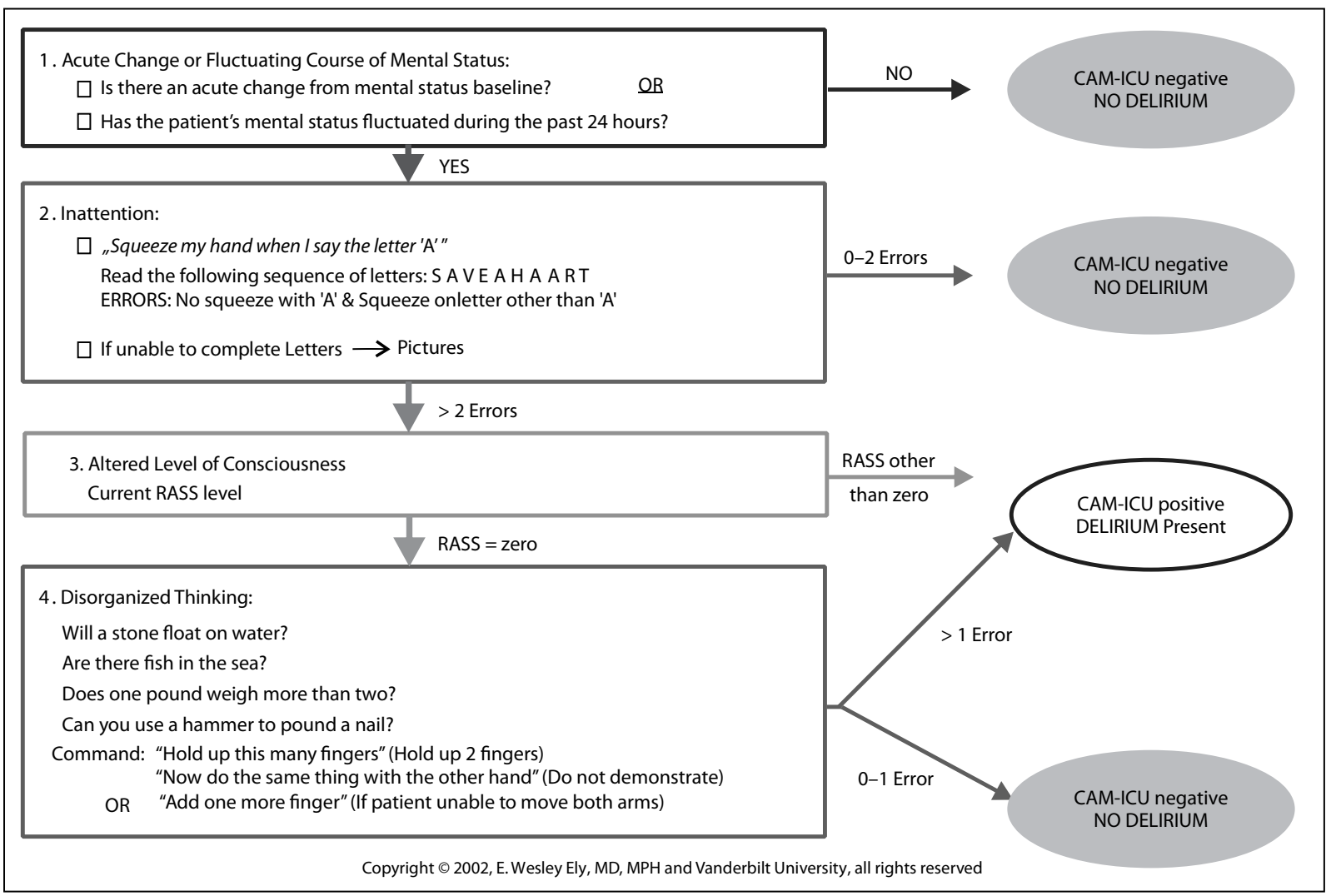

Figure 4. CAM-ICU. The Polish version of the diagnostic protocol to assess disorders of consciousness in the intensive care unit

\section{PREVENTION OF DELIRIUM}

The risk factors for delirium occur in many ICU patients; the majority of them are present already on admission and are not modifiable (age, coexisting diseases, etc.). However, there are strategies for prevention of delirium which are used in practice. The Pain, Agitation, and Delirium Guidelines from 2013 (CCM) contain no recommendations for any drug to be effective in preventing delirium [6]. The above is confirmed by the study published in JAMA in 2018 and conducted by van den Boogaart et al. [32] in the group of 1789 patients. The study findings have demonstrated that the supply of IV haloperidol at a dose of 1 or $2 \mathrm{mg}$ three times a day does not increase 28-day survival, compared to the placebo group.

The potential mechanism of drug action is based on the current understanding of the pathophysiology of delirium and assumes a decrease in the activity of dopamine and improvement of neurotransmitter balance as well as the use of drugs increasing cholinergic activity since anticholinergic agents can increase the risk of delirium (e.g. inhibitors of acetylcholinesterase) [15]. In the study involving cardiac surgery patients, risperidone supplied during recovery from general anaesthesia has been shown to reduce the incidence of delirium [33].
The efficacy of dexamethasone [34], donepezil (inhibitor of acetylcholinesterase) [35] or rivastigmine (inhibitor of cholinesterase) [36] for prevention of delirium has not been confirmed. Much attention has been paid to statins in the context of delirium due to their pleiotropic anti-inflammatory effects. The studies in ICUs have demonstrated that the treatment with statins reduces the risk of ICU delirium [37, 38]. Nevertheless, further randomised controlled studies involving large samples are required to prove that statins play a significant role in preventing delirium. Many drugs have been used that should affect the CNS pathways responsible for the development of delirium, yet none has been found to be effective. Additionally, it should be remembered that antipsychotic drugs can cause excessive sedation, prolong the QTc interval or lead to the development of neuroleptic malignant syndrome. Considering the above, the role of non-pharmacological measures for prevention of delirium should be strongly emphasised.

\section{CHOICE OF SEDATION AND DEVELOPMENT OF DELIRIUM}

The main information to remember is that the use of sedation increases the risk of delirium; both the depth and kind of sedation are of importance, which has been confirmed 
by the study carried out by Shehabi et al. in 2018 [39]. The study included more than 700 patients and analysed the depth of sedation during the first 48 hours of ICU treatment versus the incidence of delirium, possible early extubation and 180-day mortality. According to the authors, irrespective of other factors, a deeper level of sedation increases the risk of death (HR [95\% Cl] 1.29 [1.15-1.46]; $P<0.001)$ and the risk of delirium (HR [95\% Cl] 1.25 [1.10-1.43]; $P=$ 0.001 ) while decreasing the possibility of early extubation (HR [95\% Cl] 0.80 [0.73-0.87]; $P<0.001$ ) [39]. The authors conclude that, since the depth of sedation is an independent risk factor of death, delirium and delayed extubation in the ICU, the targeted level of sedation to achieve should be a RASS score of 0 .

Many studies and guidelines emphasise that benzodiazepines, especially lorazepam, significantly affect the occurrence of delirium, which has not been observed in the case of propofol or short-acting opioids. The PAD guidelines suggest that analgesia-first sedation without benzodiazepines should be used in mechanically ventilated patients [6]. According to the study comparing lorazepam and dexmedetomidine in intubated patients [40], the number of days without delirium and coma was higher in patients administered dexmedetomidine. The comparison of dexmedetomidine and midazolam showed similar effects $-54 \%$ of dexmedetomidine patients and $77 \%$ of midazolam patients developed ICU delirium $(P<0.001) 41$. In the group of cardiac surgery patients, dexmedetomidine reduced the incidence of delirium without increasing the risk of hypotension or bradycardia. Djalani et al. [42], in their randomised controlled study involving 183 patients compared dexmedetomidine versus propofol sedation in cardiac surgery patients, demonstrating shortened duration of delirium ( 2 vs. 3 days, $P=0.040$ ) and reduced incidence of delirium ( $17.5 \%$ vs. $31.5 \%, P=0.028)$ in cases of dexmedetomidine sedation.

In response to the PAD guidelines and recommendations for the use of opioid sedation, Strom et al. [43] carried out the study comparing the strategy based on boluses of morphine with the supply of propofol or midazolam. The incidence of hyperactive delirium was found to be higher in the morphine group ( $20 \%$ vs. $7 \%$; $P=0.04$ ); however, the ICU treatment in this group was significantly shorter.

A new term of rapidly reversible, sedation-related delirium has been introduced into the ICU by Patel and coworkers [44]. In their prospective cohort study assessing patients for delirium before and after the completion of sedative infusion, the incidence of delirium was extremely high $-89 \%$ of patients developed delirium yet in $12 \%$ of them the symptoms of delirium subsided after cessation of sedative infusion; this group was characterised by shorter ICU stay $(P=0.001)$, shorter duration of mechanical ventilation
$(P<0.001)$ and lower mortality $(P<0.001)$, as compared to patients with persistent delirium [44].

The ABCDEF care bundle

Numerous studies assessed interventions which reduce the incidence of delirium; some other studies assessed also the combined effect of various interventions, which enabled to develop the Awakening and Breathing Coordination, Delirium Monitoring/Management, and Early Exercise/Mobility (ABCDE) care bundle published in 2011 [45]. The authors of this concept carried out a comparative study before and after implementation of the care bundle [46]. In their study, the treatment before implementation of the $A B C D E$ care bundle meant standard therapy involving spontaneous awakening trials, (SAT) and spontaneous breathing trials (SBT); the "after " group underwent regular assessment of the depth of sedation using the RASS scale and screening for delirium using the CAM-ICU, planned treatment of delirium and early mobilisation. Patients from the "after implementation of intervention" group had fewer incidents of delirium (48.7\% vs. $62.3 \% ; P=0.02$ ) and lower percentages of ICU days with delirium (33\% vs. $50 \% ; P=0.002$ ) [46]. The studies on the $A B C D E$ care bundle were followed by initiatives facilitating the introduction of changes and by the concept of ICU liberation promoted by the Society of Critical Care Medicine; moreover, the bundle was widened with an additional element, i.e. family engagement and empowerment (F) $[45,47]$. The details are presented in Table 3.

\section{TREATMENT OF DELIRIUM}

\section{PHARMACOLOGICAL TREATMENT}

The data regarding effective pharmacological treatment of delirium are extremely scarce; therefore, the basis for ICU delirium treatment is early management of homeostasis-impairing diseases, which led to the development of delirium. There are no large randomised studies on pharmacological options for treating delirium. Delirium is treated with antipsychotic drugs - typical (e.g. haloperidol) and atypical (e.g. quetiapine, olanzapine) and dexmedetomidine (central receptor alpha-2 agonist); however, the number of studies confirming their efficacy is very limited.

The study assessing the efficacy of olanzapine $(5 \mathrm{mg}$ over $24 \mathrm{~h}$ ) and haloperidol ( 2.5 do $5 \mathrm{mg}$ every 8 hours) has not shown any differences in the duration of delirium; nevertheless, patients receiving haloperidol experienced more extrapyramidal adverse effects [48]. Another study has demonstrated the efficacy of quetiapine at a dose 2 $\times 50 \mathrm{mg}$ in terms of quicker treatment of the first episode of delirium, as compared with placebo; however, ICU stay and mortality were comparable in both groups [49]. The Dexmedetomidine to Lessen ICU Agitation (DahLIA) study randomized patients who could not be weaned from 
Table 3. ABCDEF bundle — recommendations of the Society of Critical Care Medicine of 2013

\begin{tabular}{|c|c|c|}
\hline ABCDEF bundle & Task & Action \\
\hline A & $\begin{array}{l}\text { Asses, prevent and } \\
\text { manage pain }\end{array}$ & $\begin{array}{l}\text { Assessment of pain according to CPOT or BPS } \\
\text { Provision of adequate pain management } \\
\text { Multimodal analgesia, regional anaesthesia, non-opioid adjuvants } \\
\text { Fentanyl-based analgosedation }\end{array}$ \\
\hline $\begin{array}{l}\text { Both SAT } \\
\text { and SBT }\end{array}$ & $\begin{array}{l}\text { Spontaneous awakening } \\
\text { trials and spontaneous } \\
\text { breathing trials }\end{array}$ & $\begin{array}{l}\text { Daily trials to decrease sedation and spontaneous breathing trials } \\
\text { Coordinated care to wean the patient from a ventilator } \\
\text { Dynamic reduction of ventilator support and withdrawal of mechanical ventilation }\end{array}$ \\
\hline C & Choice of sedation & $\begin{array}{l}\text { Shallow sedation to be targeted, if needed } \\
\text { Sedation monitoring( e.g. RASS) } \\
\text { Avoidance of benzodiazepines } \\
\text { Dexmedetomidine, in cases of a high risk of delirium, cardiac surgery, weaning from a ventilator }\end{array}$ \\
\hline D & $\begin{array}{l}\text { Delirium monitoring and } \\
\text { management }\end{array}$ & $\begin{array}{l}\text { Routine assessment of delirium using CAM-ICU or ICDSC } \\
\text { Non-pharmacological management } \\
\text { Improved sleep hygiene } \\
\text { Dexmedetomidine or antipsychotic drugs, in cases of hyperactive delirium }\end{array}$ \\
\hline $\mathbf{E}$ & Early mobility and exercise & $\begin{array}{l}\text { Gradually from passive to active exercises, increasing the range of motion } \\
\text { Exercises coordinated with sedation interruptions or absence of sedation } \\
\text { Occupational therapy } \\
\text { Everyday activities }\end{array}$ \\
\hline $\mathbf{F}$ & $\begin{array}{l}\text { Family engagement and } \\
\text { empowerment }\end{array}$ & $\begin{array}{l}\text { Reorientation of patients regarding their disease and condition } \\
\text { Emotional and spiritual support } \\
\text { Involvement in stimulation of cognitive functions and early mobility } \\
\text { Participation in ICU visits }\end{array}$ \\
\hline
\end{tabular}

CPOT — Critical-Care Pain Observation Tool; BPS — Behavioral Pain Scale; SAT — spontaneous awakening trial; SBT — spontaneous breathing trial

a ventilator due to hyperactive delirium and agitation to receive dexmedetomidine (at a dose up to $1.5 \mu \mathrm{g} \mathrm{kg}^{-1} \mathrm{~h}^{-1}$ ) administered for 7 days or placebo [50]. The patients treated with dexmedetomidine demonstrated quicker subsidence of delirium symptoms and longer time without a ventilator; moreover, the incidence of adverse effects did not increase (bradycardia, hypotension) [50]. Still another randomized study was carried out in patients with hyperactive delirium breathing spontaneously (they were not intubated) [51]. The patients who did not respond to intravenous supply of $30 \mathrm{mg}$ of haloperidol received dexmedetomidine at a dose ranging from 0.2 to $0.7 \mu \mathrm{g} \mathrm{kg}^{-1} \mathrm{~h}^{-1}$, while those who reacted to haloperidol were administered an infusion of haloperidol ( 0.5 to 1 $\left.\mathrm{mg} \mathrm{h}^{-1}\right)$. The dexmedetomidine patients had shorter ICU treatment times and fewer episodes of excessive sedation [51].

The Pain, Agitation, and Delirium guidelines do not contain recommendations for the use of any drug to treat delirium. Furthermore, there are no data about the efficacy of any drug for prevention of delirium. To sum up, according to the PAD guidelines [6]:

- the use of rivastigmine is not recommended for treatment of delirium;

- there are no explicit recommendations for or against the use of haloperidol, classical antipsychotic drugs or other atypical antipsychotic drugs; haloperidol has traditionally been used as first-line therapy of delirium yet it does not shorten the duration of delirium;

- as far as new antipsychotic drugs are concerned, e.g. quetiapine, there are studies involving small populations demonstrating that their administration shortens the duration of delirium;

- dexmedetomidine, as a highly selective agonist of a2adrenergic receptors, which ensures cooperative sedation, is preferred over benzodiazepines.

The exceptional cases in which benzodiazepines are recommended include alcohol withdrawal delirium and benzodiazepine dependence syndrome, which is particularly common in older individuals.

Once pharmacological treatment has been started, it should be remembered that the definition of delirium includes altered mental status; therefore, the patient is considered cured when CAM-ICU is negative for 24 hours. When during one staff shift, the result is positive and during the next shift the result is negative, monitoring of delirium should be continued and further pharmacological treatment should be considered until the patient has negative CAM-ICU results for 24 hours. During this period, the dose of drugs administered can certainly be reduced. Due to the lack of large, multi-centre analyses, this issue requires further in-depth studies, which would allow to decide about the most appropriate choice of drugs to treat delirium or about their withdrawal as quickly as possible.

\section{NON-PHARMACOLOGICAL TREATMENT}

The treatment of delirium is based on early diagnosis and limitation of risk factors, such as dehydration, immobilisation, disorders of sleep, vision or hearing. The environmental factors considerably affect the development of delirium; 
therefore, the personnel of ICUs, physicians, nurses and rehabilitants, should aim at providing the optimal environment to limit the number of unnecessary stimuli reaching the patient's central nervous system. The management strategies include limitation of noise, exposure to natural light during the day and night hours, provision of room temperature and undisturbed night rest. The further elements are adequate daily rehabilitation, occupational therapy or presence of family members. It is essential to ensure efficient communication with the environment, including daily orientation to place, time and his/her condition, provision of glasses and hearing aids, whenever used earlier. Special attention should be paid to intubated and mechanically ventilated patients as well as patients with myopathy. During this difficult period, the assistance of a psychologist and occupational therapy should be essential.

\section{EARLY AMBULATION}

The time of commencing rehabilitation in ICU patients depends on their conditions and availability of physiotherapists. Early rehabilitation of mechanically ventilated patients planned by the entire therapeutic team, i.e. physiotherapists, nurses and physicians, has been found feasible and safe. Early rehabilitation limits weakness often observed in severely ill patients [52]. It is essential to introduce interruptions of sedation (whenever possible) or limit sedation to a minimum and gradually increase the range of mobility- starting with passive exercises, followed by active ones, exercises in bed, sitting, standing, attempts to walk, learning everyday activities and occupational therapy. The multicentre randomised study carried out by Schweickert et al. [53] has revealed that daily rehabilitation and occupational therapy during daily sedation interruptions shortened ICU delirium by 2 days, on average ( 4 days of ICU delirium in the group without interruption of sedation and rehabilitation versus 2 days in the intervention group, $P=0.03$ ).

\section{SLEEP HYGIENE}

The available studies have shown that impaired quality of sleep resulting from a severe disease, sedation and an unfriendly ICU environment can be associated with the occurrence of delirium. Sleep fragmentation caused by noise, bright light, lack of quality nocturnal breaks, and drugs was analysed. Various drugs used for sedation have been found to affect ICU sleep. Propofol, induces seemingly quiet sleep yet substantially shortens the REM phases and their incidences while dexmedetomidine decreases sleep fragmentation, improves the quality of sleep, and lengthens the non-REM phase, which makes its effects similar to the physiological sleep $[55,56]$. The use of ear plugs as an isolated intervention or part of the intervention bundle, reduces the incidence of ICU delirium [54]. The study results regarding melatonin are conflicting; the outflow of melatonin is abnormal in septic patients and its concentration reduced in delirium patients; however, its administration as a drug has not reduced the incidence of delirium. Ramelteon - an agonist of melatonin, can exert protective effects in older individuals, which confirms a possible role of melatonin in the pathogenesis of delirium [57]. Moreover, suvorexant - a potent selective antagonist of the orexin receptor is a newly developed agent considered for prevention of delirium yet further studies are needed to confirm its effects [58]. A study by Skrobik et al. [59] reported that nocturnal administration of low-dose dexmedetomidine (titrated to RASS-1 or a maximum dose of $0.7 \mu \mathrm{g} \mathrm{kg}^{-1} \mathrm{~h}^{-1}$ ) reduced the incidence of ICU delirium in critically ill patients, but did not improve sleep quality [59]. There is no doubt that in order to provide ICU patients with adequate night rest, a multifactorial project of sleep quality improvement is required involving provision of nocturnal silence, use of ear stoppers and eye masks, minimisation of nocturnal interventions, promotion of normal circadian rhythms and suitable pharmacological management.

\section{PROTOCOL FOR TREATMENT OF ICU DELIRIUM}

All the studies concerning a reduction in incidences of delirium and its effective treatment explicitly show low efficacy of single interventions, as opposed to substantially more effective coordinated interventions $[60,61]$. The compilation of various types of interventions for prevention and treatment of delirium is presented in Figure 5, based on the ABCDEF care bundle. The additional argument against pharmacological treatment is the presence of severe adverse side effects of antipsychotic drugs used for the treatment of delirium prolonged QTc interval, potential risk of ventricular arrhythmia, respiratory disturbances, risk of neuroleptic malignant syndrome or dexmedetomidine-induced bradycardia. The current studies support the role of dexmedetomidine for prevention and management of delirium; nevertheless, further studies are needed regarding the efficacy of other drugs from the group of $a_{2}$-agonists, such as clonidine or guanfacine, as intravenous administration of dexmedetomidine in continuous infusions that is required is its main limitation, especially in patinets discharged from ICUs with persistent delirium. It is worth re-emphasizing that pharmacological treatment should be the last and not the first choice and that therapy should be based on preventive measures using non-pharmacological strategies and interventions.

\section{SUMMARY}

It has been recognised that ICU delirium is a common and severe clinical manifestation of acute brain dysfunction bearing long-term consequences. Therefore, routine monitoring for delirium is part of assessment of the status 


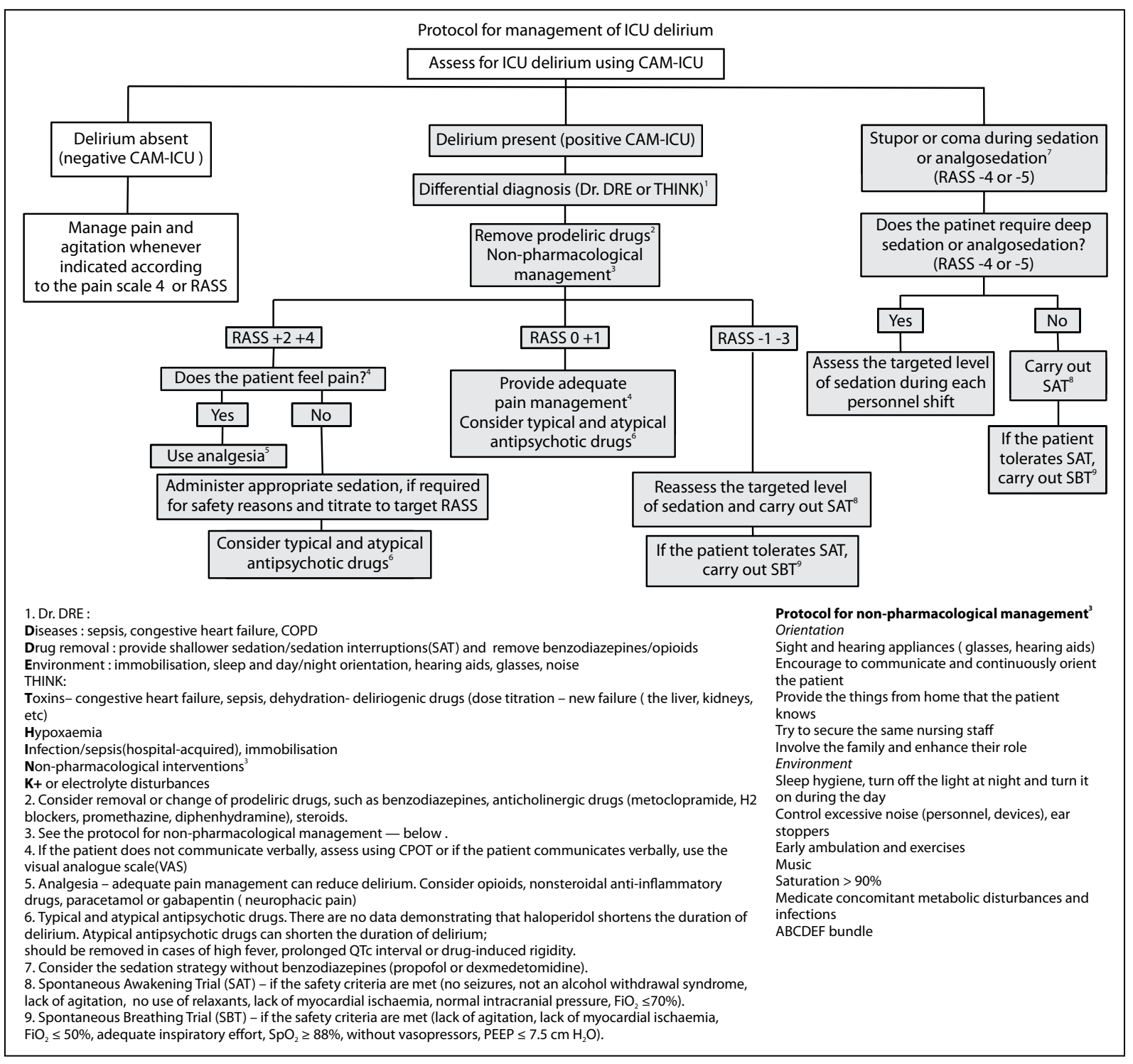

Figure 5. The management protocol for ICU delirium. Source: www.icudelirium.org

of ICU patients; however, the stigma of delirium extends beyond intensive care units and affects patients hospitalised in other departments, particularly elderly individuals. Many departments should routinely monitor their patients for delirium and implement preventive strategies, such as the $A B C D E F$ care bundle to prevent and manage delirium. The prevention of ICU delirium by identification of the level of risk, avoidance of causative factors of delirium, early implementation of multifactorial therapy and possibly pharmacological treatment should belong to standard strategies of the entire medical personnel, especially physicians, since hospital admission.

\section{ACKNOWLEDGEMENTS}

1. For assistance. Fragments of the "Confusion Assessment Method (CAM-ICU) a complete manual, 2014"developed by the ICU Delirium Study Group of the Vanderbilt University, USA, were used in the article. The Polish version of the manual was prepared by the team consisting of Katarzyna Kotfis, MD, PhD, Jowita Biernawska, MD, PhD., Małgorzata Zegan-Barańska, MD, PhD, prof. Maciej Żukowski, MD, PhD, prof. Joanna Rymaszewska, MD, PhD, prof. Andrzej Potemkowski, MD, PhD. The materials for practical application of CAM-ICU are available on: http://www.icudelirium.org/delirium/languages.html and http://www.proicu.pl.

2. Source of funding - none.

3. Conflict of interest - none declared.

\section{References:}

1. Ely EW, Shintani A, Truman B, et al. Delirium as a predictor of mortality in mechanically ventilated patients in the intensive care unit. JAMA. 2004; 291(14): 1753-1762, doi: 10.1001/jama.291.14.1753, indexed in Pubmed: 15082703. 
2. Girard TD, Jackson JC, Pandharipande PP, et al. Delirium as a predictor of long-term cognitive impairment in survivors of critical illness. Crit Care Med. 2010; 38(7): 1513-1520, doi: 10.1097/CCM.0b013e3181e47be1, indexed in Pubmed: 20473145.

3. Pandharipande PP, Girard TD, Jackson JC, et al. BRAIN-ICU Study Investigators. Long-term cognitive impairment after critical illness. N Engl J Med. 2013; 369(14): 1306-1316, doi: 10.1056/NEJMoa1301372, indexed in Pubmed: 24088092

4. Kotfis K, Zegan-Barańska M, Żukowski M, et al. Multicenter assessment of sedation and delirium practices in the intensive care units in Poland - is this common practice in Eastern Europe? BMC Anesthesiol. 2017; 17(1): 120, doi: 10.1186/s12871-017-0415-2, indexed in Pubmed: 28865447.

5. Morandi A, Piva S, Ely EW, et al. Worldwide Survey of the „Assessing Pain, Both Spontaneous Awakening and Breathing Trials, Choice of Drugs, Delirium Monitoring/Management, Early Exercise/Mobility, and Family Empowerment" (ABCDEF) Bundle. Crit Care Med. 2017; 45(11): e1111-e1122, doi: 10.1097/CCM.0000000000002640, indexed in Pubmed: 28787293.

6. Barr J, Fraser GL, Puntillo K et al.; American College of Critical Care Medicine. Clinical practice guidelines for the management of pain, agitation, and delirium in adult patients in the intensive care unit. Crit Care Med. 2013 Jan;41(1):263-306. doi: 10.1097/CCM.0b013e3182783b72, indexed in Pubmed: 23269131.

7. Baron R, Binder A, Biniek R, et al. DAS-Taskforce 2015. Evidence and consensus based guideline for the management of delirium, analgesia, and sedation in intensive care medicine. Revision 2015 (DAS-Guideline 2015) — short version. Ger Med Sci. 2015; 13: Doc19, doi: 10.3205/000223, indexed in Pubmed: 26609286.

8. Vincent JL, Shehabi Y, Walsh TS, et al. Comfort and patient-centred care without excessive sedation: the eCASH concept. Intensive Care Med. 2016; 42(6): 962-971, doi: 10.1007/s00134-016-4297-4, indexed in Pubmed: 27075762.

9. American Psychiatric Association: Diagnostic and Statistical Manual of Mental Disorders, 5th edition. Washington, D.C., American Psychiatric Association, 2013.

10. Peterson JF, Pun BT, Dittus RS, et al. Delirium and its motoric subtypes: a study of 614 critically ill patients. J Am Geriatr Soc. 2006; 54(3): 479-484, doi: 10.1111/j.1532-5415.2005.00621.x, indexed in Pubmed: 16551316.

11. Card E, Pandharipande P, Tomes $C$, et al. Emergence from general anaesthesia and evolution of delirium signs in the post-anaesthesia care unit. Br J Anaesth. 2015; 115(3): 411-417, doi: 10.1093/bja/aeu442, indexed in Pubmed: 25540068.

12. Salluh Jl, Soares M, Teles JM, et al. Delirium Epidemiology in Critical Care Study Group. Delirium epidemiology in critical care (DECCA): an international study. Crit Care. 2010; 14(6): R210, doi: 10.1186/cc9333, indexed in Pubmed: 21092264.

13. Robinson TN, Raeburn CD, Tran ZV, et al. Motor subtypes of postoperative delirium in older adults. Arch Surg. 2011; 146(3): 295-300, doi: 10.1001/archsurg.2011.14, indexed in Pubmed: 21422360.

14. Marra A, Ely EW, Pandharipande PP, et al. The ABCDEF Bundle in Critical Care. Crit Care Clin. 2017; 33(2): 225-243, doi: 10.1016/j.ccc.2016.12.005, indexed in Pubmed: 28284292.

15. Hayhurst $\mathrm{CJ}$, Pandharipande PP, Hughes CG. Intensive care unit delirium: a review of diagnosis, prevention, and treatment. Anesthesiology. 2016; 125(6): 1229-1241, doi: 10.1097/ALN.0000000000001378, indexed in Pubmed: 27748656

16. Vasilevskis EE, Han $\mathrm{JH}$, Hughes $\mathrm{CG}$, et al. Epidemiology and risk factors for delirium across hospital settings. Best Pract Res Clin Anaesthesiol. 2012; 26(3): 277-287, doi: 10.1016/j.bpa.2012.07.003, indexed in Pubmed: 23040281.

17. Jones RN, Fong TG, Metzger E, et al. Aging, brain disease, and reserve: implications for delirium. Am J Geriatr Psychiatry. 2010; 18(2): 117-127, doi: 10.1097/JGP.0b013e3181b972e8, indexed in Pubmed: 20104068.

18. Vaurio $L E$, Sands $L P$, Wang $Y$, et al. Postoperative delirium: the importance of pain and pain management. Anesth Analg. 2006; 102(4): 1267-1273, doi: 10.1213/01.ane.0000199156.59226.af, indexed in Pubmed: 16551935

19. Pandharipande PP, Pun BT, Herr DL, et al. Effect of sedation with dexmedetomidine vs lorazepam on acute brain dysfunction in mechanically ventilated patients: the MENDS randomized controlled trial. JAMA. 2007; 298(22): 2644-2653, doi: 10.1001/jama.298.22.2644, indexed in Pubmed: 18073360.
20. Van Rompaey B, Schuurmans MJ, Shortridge-Baggett LM, et al. Risk factors for intensive care delirium: a systematic review. Intensive Crit Care Nurs. 2008;24(2): 98-107, doi: 10.1016/j.iccn.2007.08.005, indexed in Pubmed: 17949984.

21. Riker RR, Shehabi Y, Bokesch PM, et al. SEDCOM (Safety and Efficacy of Dexmedetomidine Compared With Midazolam) Study Group. Dexmedetomidine vs midazolam for sedation of critically ill patients: a randomized trial. JAMA. 2009; 301(5): 489-499, doi: 10.1001/jama.2009.56, indexed in Pubmed: 19188334.

22. Steinberg BE, Sundman E, Terrando N, et al. Neural control of inflammation: implications for perioperative and critical care. Anesthesiology. 2016; 124(5): 1174-1189, doi: 10.1097/ALN.0000000000001083, indexed in Pubmed: 26982508.

23. Schreiber MP, Colantuoni E, Bienvenu OJ, et al. Corticosteroids and transition to delirium in patients with acute lung injury. Crit Care Med. 2014;42(6): 1480-1486, doi: 10.1097/CCM.0000000000000247, indexed in Pubmed: 24589640.

24. Flacker JM, Lipsitz LA. Neural mechanisms of delirium: current hypotheses and evolving concepts. J Gerontol A Biol Sci Med Sci. 1999; 54(6): B239-B246, indexed in Pubmed: 10411009.

25. Hshieh TT, Fong TG, Marcantonio ER, et al. Cholinergic deficiency hypothesis in delirium: a synthesis of current evidence. J Gerontol A Biol Sci Med Sci. 2008; 63(7): 764-772, indexed in Pubmed: 18693233.

26. Luetz A, Heymann A, Radtke FM, et al. Different assessment tools for intensive care unit delirium: which score to use? Crit Care Med. 2010; 38(2): 409-418, doi: 10.1097/CCM.0b013e3181cabb42, indexed in Pubmed: 20029345.

27. Ely EW, Inouye SK, Bernard GR, et al. Delirium in mechanically ventilated patients: validity and reliability of the confusion assessment method for the intensive care unit (CAM-ICU). JAMA. 2001; 286(21):2703-2710, indexed in Pubmed: 11730446.

28. Bergeron N, Dubois MJ, Dumont M, et al. Intensive Care Delirium Screening Checklist: evaluation of a new screening tool. Intensive Care Med. 2001; 27(5): 859-864, indexed in Pubmed: 11430542.

29. Inouye SK, van Dyck CH, Alessi CA, et al. Clarifying confusion: the confusion assessment method. A new method for detection of delirium. Ann Intern Med. 1990; 113(12): 941-948, indexed in Pubmed: 2240918.

30. Gusmao-Flores D, Salluh Jl, Chalhub RÁ, et al. The confusion assessment method for the intensive care unit (CAM-ICU) and intensive care delirium screening checklist (ICDSC) for the diagnosis of delirium: a systematic review and meta-analysis of clinical studies. Crit Care. 2012; 16(4): R115, doi: 10.1186/cc11407, indexed in Pubmed: 22759376.

31. Brummel $\mathrm{NE}$, Vasilevskis EE, Han JHo, et al. Implementing delirium screening in the ICU: secrets to success. Crit Care Med. 2013; 41(9): 2196-2208, doi: 10.1097/CCM.0b013e31829a6f1e, indexed in Pubmed: 23896832.

32. van den Boogaard M, Slooter AJC, Brüggemann RJM, et al. REDUCE Study Investigators. Effect of Haloperidol on Survival Among Critically III Adults With a High Risk of Delirium: The REDUCE Randomized Clinical Trial. JAMA. 2018; 319(7):680-690, doi: 10.1001/jama.2018.0160, indexed in Pubmed: 29466591.

33. Hakim SM, Othman Al, Naoum DO. Early treatment with risperidone for subsyndromal delirium after on-pump cardiac surgery in the elderly: a randomized trial. Anesthesiology. 2012; 116(5): 987-997, doi: 10.1097/ ALN.0b013e31825153cc, indexed in Pubmed: 22436797.

34. Sauër AMC, Slooter AJC, Veldhuijzen DS, et al. Intraoperative dexamethasone and delirium after cardiac surgery: a randomized clinical trial. Anesth Analg. 2014; 119(5): 1046-1052, doi: 10.1213/ ANE. 0000000000000248 , indexed in Pubmed: 24810262

35. Liptzin B, Laki A, Garb JL, et al. Donepezil in the prevention and treatment of post-surgical delirium. Am J Geriatr Psychiatry. 2005; 13(12): 1100-1106, doi: 10.1176/appi.ajgp.13.12.1100, indexed in Pubmed: 16319303.

36. Gamberini $M$, Bolliger D, Lurati Buse GA, et al. Rivastigmine for the prevention of postoperative delirium in elderly patients undergoing elective cardiac surgery--a randomized controlled trial. Crit Care Med. 2009; 37(5): 1762-1768, doi: 10.1097/CCM.0b013e31819da780, indexed in Pubmed: 19325490.

37. Page VJ, Davis $D$, Zhao XB, et al. Statin use and risk of delirium in the critically ill. Am J Respir Crit Care Med. 2014; 189(6): 666-673, doi: 10.1164/rccm.201306-11500C, indexed in Pubmed: 24417431.

38. Morandi A, Hughes CG, Thompson $\mathrm{JL}$, et al. Statins and delirium during critical illness: a multicenter, prospective cohort study. Crit Care Med. 
2014;42(8): 1899-1909, doi: 10.1097/CCM.0000000000000398, indexed in Pubmed: 24810528.

39. Shehabi Y, Bellomo R, Kadiman S et al.; Sedation Practice in Intensive Care Evaluation (SPICE) Study Investigators and the Australian and New Zealand Intensive Care Society Clinical Trials Group. Sedation Intensity in the First 48 Hours of Mechanical Ventilation and 180-Day Mortality: A Multinational Prospective Longitudinal Cohort Study. Crit Care Med. 2018 Jun; 46(6): 850-859. doi: 10.1097/CCM.0000000000003071.

40. Pandharipande PP, Pun BT, Herr DL, et al. Effect of sedation with dexmedetomidine vs lorazepam on acute brain dysfunction in mechanically ventilated patients: the MENDS randomized controlled trial. JAMA. 2007; 298(22): 2644-2653, doi: 10.1001/jama.298.22.2644, indexed in Pubmed: 18073360.

41. Riker RR, Shehabi Y, Bokesch PM, et al. SEDCOM (Safety and Efficacy of Dexmedetomidine Compared With Midazolam) Study Group. Dexmedetomidine vs midazolam for sedation of critically ill patients: a randomized trial. JAMA. 2009; 301(5): 489-499, doi: 10.1001/jama.2009.56, indexed in Pubmed: 19188334

42. Djaiani G, Silverton N, Fedorko L, et al. Dexmedetomidine versus propofol sedation reduces delirium after cardiac surgery: a randomized controlled trial. Anesthesiology. 2016; 124(2): 362-368, doi: 10.1097/ ALN.0000000000000951, indexed in Pubmed: 26575144.

43. Strøm T, Martinussen T, Toft P. A protocol of no sedation for critically ill patients receiving mechanical ventilation: a randomised trial. Lancet. 2010; 375(9713): 475-480, doi: 10.1016/S0140-6736(09)62072-9, indexed in Pubmed: 20116842

44. Patel SB, Poston JT, Pohlman A, et al. Rapidly reversible, sedation-related delirium versus persistent delirium in the intensive care unit. Am J Respir Crit Care Med. 2014; 189(6): 658-665, doi: 10.1164/rccm.201310-18150C, indexed in Pubmed: 24423152.

45. Morandi A, Brummel NE, Ely EW. Sedation, delirium and mechanical ventilation: the,ABCDE' approach. Curr Opin Crit Care. 2011; 17(1): 43-49, doi: 10.1097/MCC.0b013e3283427243, indexed in Pubmed: 21169829.

46. Balas MC, Vasilevskis EE, Olsen KM, et al. Implementing the awakening and breathing coordination, delirium monitoring/management, and early exercise/mobility bundle into everyday care: opportunities, challenges, and lessons learned for implementing the ICU Pain, Agitation, and Delirium Guidelines. Crit Care Med. 2013; 41 (9 Suppl 1): S116-S127, doi: 10.1097/CCM.0b013e3182a17064, indexed in Pubmed: 23989089.

47. Barnes-Daly MA, Phillips G, Ely EW. Improving Hospital Survival and Reducing Brain Dysfunction at Seven California Community Hospitals: Implementing PAD Guidelines Via the ABCDEF Bundle in 6,064 Patients. Crit Care Med. 2017; 45(2): 171-178, doi: 10.1097/ CCM.0000000000002149, indexed in Pubmed: 27861180.

48. Skrobik YK, Bergeron N, Dumont M, et al. Olanzapine vs haloperidol: treating delirium in a critical care setting. Intensive Care Med. 2004; 30(3): 444-449, doi: 10.1007/s00134-003-2117-0, indexed in Pubmed: 14685663.

49. Devlin JW, Roberts RJ, Fong JJ, et al. Efficacy and safety of quetiapine in critically ill patients with delirium: a prospective, multicenter, randomized, double-blind, placebo-controlled pilot study. Crit Care Med. 2010; 38(2): 419-427, doi: 10.1097/CCM.0b013e3181b9e302, indexed in Pubmed: 19915454.

50. Reade MC, Eastwood GM, Bellomo R, et al. DahLIA Investigators, Australian and New Zealand Intensive Care Society Clinical Trials Group. Effect of Dexmedetomidine Added to Standard Care on Ventilator-Free Time in Patients With Agitated Delirium: A Randomized Clinical Trial. JAMA. 2016; 315(14): 1460-1468, doi: 10.1001/jama.2016.2707, indexed in Pubmed: 26975647.
51. Carrasco G, Baeza N, Cabré L, et al. Dexmedetomidine for the treatment of hyperactive delirium refractory to haloperidol in nonintubated icu patients: a nonrandomized controlled trial. Crit Care Med. 2016; 44(7): 1295-1306, doi: 10.1097/CCM.0000000000001622, indexed in Pubmed: 26925523.

52. Azoulay E, Vincent JL, Angus DC, et al. Recovery after critical illness: putting the puzzle together-a consensus of 29. Crit Care. 2017; 21(1): 296, doi: 10.1186/s13054-017-1887-7, indexed in Pubmed: 29208005.

53. Pohlman MC, Schweickert WD, Pohlman AS, et al. Early physical and occupational therapy in mechanically ventilated, critically ill patients: a randomised controlled trial. Lancet. 2009; 373(9678): 1874-1882, doi: 10.1016/S0140-6736(09)60658-9, indexed in Pubmed: 19446324.

54. Litton E, Carnegie V, Elliott R, et al. The efficacy of earplugs as a sleep hygiene strategy for reducing delirium in the ICU: A Systematic Review and Meta-Analysis. Crit Care Med. 2016; 44(5): 992-999, doi: 10.1097/ CCM.0000000000001557, indexed in Pubmed: 26741578.

55. Kondili E, Alexopoulou C, Xirouchaki N, et al. Effects of propofol on sleep quality in mechanically ventilated critically ill patients: a physiological study. Intensive Care Med. 2012; 38(10): 1640-1646, doi: 10.1007/ s00134-012-2623-z, indexed in Pubmed: 22752356.

56. Alexopoulou C, Kondili E, Diamantaki E, et al. Effects of dexmedetomidine on sleep quality in critically ill patients: a pilot study. Anesthesiology. 2014; 121(4): 801-807, doi: 10.1097/ALN.0000000000000361, indexed in Pubmed: 24988068.

57. Hatta K, Kishi Y, Wada K, et al. DELIRIA-J Group. Preventive effects of ramelteon on delirium: a randomized placebo-controlled trial. JAMA Psychiatry. 2014; 71(4): 397-403, doi: 10.1001/jamapsychiatry.2013.3320, indexed in Pubmed: 24554232.

58. Hatta K, Kishi Y, Wada K, et al. DELIRIA-J Group. Preventive effects of suvorexant on delirium: a randomized placebo-controlled trial. J Clin Psychiatry. 2017; 78(8): e970-e979, doi: 10.4088/JCP.16m11194, indexed in Pubmed: 28767209.

59. Skrobik Y, Duprey MS, Hill NS, et al. Low-dose nocturnal dexmedetomidine prevents ICU delirium. A randomized, placebo-controlled trial. Am J Respir Crit Care Med. 2018; 197(9): 1147-1156, doi: 10.1164/ rccm.201710-19950C, indexed in Pubmed: 29498534.

60. Inouye SK, Bogardus ST, Charpentier PA, et al. A multicomponent intervention to prevent delirium in hospitalized older patients. $\mathrm{N} \mathrm{Engl}$ J Med. 1999; 340(9): 669-676, doi: 10.1056/NEJM199903043400901, indexed in Pubmed: 10053175.

61. Jacobi J, Fraser GL, Coursin DB, et al. Task Force of the American College of Critical Care Medicine (ACCM) of the Society of Critical Care Medicine (SCCM), American Society of Health-System Pharmacists (ASHP), American College of Chest Physicians. Clinical practice guidelines for the sustained use of sedatives and analgesics in the critically ill adult. Crit Care Med. 2002; 30(1): 119-141, indexed in Pubmed: 11902253.

\section{Corresponding author:}

Katarzyna Kotfis, MD, PhD, DESA

Department of Anesthesiology,

Intensive Therapy and Acute Intoxications,

Pomeranian Medical University in Szczecin, Poland

e-mail:katarzyna.kotfis@pum.edu.pl

Received: 25.03 .2018

Accepted: 30.04 .2018 